\title{
Optical Properties of the Rubidium and Cesium Halides in the Extreme Ultraviolet*
}

\author{
M. Cardona, $\dagger^{\dagger}$ R. Haensel, D. W. Lynch, ${ }^{\dagger}$ and B. Sonntag \\ Deutsches Elektronen-Synchrotron, Hamburg, Germany \\ and \\ II. Institut für Experimentalphysik der Universität Hamburg, Hamburg, Germany \\ (Received 16 March 1970)
}

\begin{abstract}
The absorption spectra of evaporated thin films of all rubidium and cesium halides in the $50-$ to $250-\mathrm{eV}$ region are reported. In this range, transitions from the $3 d$ shell of $\mathrm{Rb}^{+}$and from the $4 d$ and $4 p$ shells of $\mathrm{Cs}^{*}$ can be seen, as well as some transitions from inner shells of the halogen ions. Besides the absorption fine structure near the threshold for inner-shell transitions, broad absorption structure is observed and explained as due to $d \rightarrow f$ continuum transitions. The number of effective electrons whose oscillator strength has been exhausted in our spectral region has been computed from the absorption data; it is particularly strong for materials containing either Cs or I. Differences in the spectra of materials with $\mathrm{NaCl}$ and with $\mathrm{CsCl}$ structure are discussed. The measurements were performed using the DESY electron synchrotron as a light source.
\end{abstract}

\section{INTRODUCTION}

The electronic optical properties of the alkali halides have been studied experimentally and theoretically for many years. These studies have been concerned both with the behavior of pure crystals ${ }^{1}$ and with the additional effects produced by defects and impurities. ${ }^{2}$ Most measurements were performed using conventional absorption techniques. Measurements of the spectral yield for photoelectric emission and the energy distribution of the photoemitted electrons have also contributed to our knowledge of the electronic structure of the alkali halides. ${ }^{3}$ More recently, transmission $^{4}$ and reflection ${ }^{5}$ modulation experiments and two-photon absorption spectroscopy ${ }^{6}$ have appeared as valuable techniques for studying these materials.

The alkali halides consist of ions with closed outer electron shells, and therefore the pure crystals (which will be exclusively considered in this work) only begin to absorb in the uv, at about $6 \mathrm{eV}$. LiF has actually a band gap of about $12 \mathrm{eV}$. Most of the reported measurements have been made in the uv and vacuum-uv range up to $25 \mathrm{eV}$. They cover transitions with initial states in the valence bands (outermost shells of the halogen ions). Whereas the pioneering investigations of the Hilsch-Pohl school ${ }^{7}$ were done by absorption spectroscopy of thin films, recent measurements of the reflection spectra of single crystals ${ }^{8-10}$ seem to show more details, thus indicating some sensitivity of the observed structure to crystalline perfection. Beside optical studies, electron energyloss measurements ${ }^{11,12}$ also allow the evaluation of the optical constants of the alkali halides in the energy range up to $20 \mathrm{eV}$.
While simple charge-transfer models and atomic considerations were used for the earlier interpretation of the experimental data, the recent availability of calculated band structures for the alkali halides makes a detailed interpretation of the observed spectra in terms of these band structures highly desirable. Such interpretation has proven very successful for covalent materials. ${ }^{13}$ The existence of strong clearly identifiable exciton effects at the threshold for interband transitions raises the question of how much of the observed optical behavior can be related to one-electron interband transitions. This question will not be answered until reliable calculations of optical constants from the one-electron band structure become available. ${ }^{14}$ In the meantime, an attempt is usually made to classify the excitons into Wannier (hydrogenic) series tied to a given interband critical point. The onset of interband transitions is then viewed as the convergence limit of the exciton series. Band calculations have been performed for $\mathrm{RbF},{ }^{15} \mathrm{RbCl}, \mathrm{RbBr},{ }^{16} \mathrm{RBI},{ }^{17} \mathrm{CsF}$ (all with the rocksalt structure), ${ }^{15,18}$ and for CsI (with both the rocksalt and the $\mathrm{CsCl}$ structure). ${ }^{19,20}$ All these calculations show the bottom of the conduction band at $\Gamma$. The wave functions at this minimum, with $\Gamma_{1}$ orbital symmetry $\left(\Gamma_{6}^{+}\right.$double-group symmetry), are mostly composed of $s$-wave functions of the metallic ion. The top of the valence band occurs also at $\Gamma$; it has $\Gamma_{15}$ orbital symmetry ( $\Gamma_{8}^{-}$double group) and corresponds largely to $p$ wave functions of the halogen ion. The spin-orbit splitting of the $\Gamma_{15}$ states into $\Gamma_{8}^{-}$and $\Gamma_{6}^{-}$is close to the corresponding splitting of the halogen ion; approximately $0.05 \mathrm{eV}$ for $\mathrm{F}^{-}, 0.1 \mathrm{eV}$ for $\mathrm{Cl}^{-}, 0.5 \mathrm{eV}$ for $\mathrm{Br}^{-}$, and $1.0 \mathrm{eV}$ for $\mathrm{I}^{-}$. According to these considerations, the lowest-energy peak observed 
in the spectrum of the $\mathrm{Rb}$ and $\mathrm{Cs}$ halides ${ }^{8-10,21-24}$ is generally interpreted as an exciton formed from the upper $\left(\Gamma_{8}^{-}\right)$branch of the $\Gamma_{15}$ valence bands and the bottom of the conduction band $\left(\Gamma_{6}^{+}\right)$. In the fluorides the spin-orbit mates $\left(\Gamma_{8}^{-}-\Gamma_{6}^{-}\right)$are very close together and therefore the $\Gamma_{8}^{-}-\Gamma_{6}^{-}$splitting cannot be resolved: In the chlorides this splitting can easily be seen at low temperatures. In reflection measurements on single crystals of the bromides and iodides, a much smaller second peak has been recognized after the first peak ${ }^{8-10}$; it has been interpreted as the $n=2$ member of a Rydberg series ${ }^{25}$ associated with the $\Gamma_{8}^{-}-\Gamma_{6}^{+}$band edge:

$$
E_{n}=E_{0}-G / n^{2}, \quad n=1,2, \ldots,
$$

where $E_{n}$ is the energy of the $n$th exciton, $E_{0}$ is the energy of the series limit (the band-gap energy), and $G$ is the binding energy of the first exciton. The observation of higher $(n>2)$ excitons in thinfilm absorption has only been possible for $\mathrm{RbI}{ }^{24}$ In contrast, for the solid rare gases ${ }^{26-28}$ - materials with otherwise similar optical properties exciton series with members up to $n=4$ have been easily observed.

For the bromides and iodides, the spin-orbit splitting is big enough to shift the $\Gamma_{6}^{-}-\Gamma_{6}^{+}$exciton into a region where other peaks, apparently not related to the $\Gamma_{15} \rightarrow \Gamma_{1}$ edge, can be seen. In this case, the identification of the high-energy component of the $\Gamma_{15}-\Gamma_{1}$ exciton among the other neighboring structures is not always possible without being ambiguous. For instance, in RbI, Baldini and Bosacchi first interpreted a peak at $6.6 \mathrm{eV}$ as an exciton, ${ }^{8}$ related to band edges at $X$ and later as a spin-orbit mate of the $\Gamma_{8}^{-}-\Gamma_{6}^{+}$exciton ${ }^{9}$ because of its temperature behavior. ${ }^{23}$ The original identification of excitons tied to interband critical points at $L$ made by Phillips ${ }^{29}$ seems to have been abandoned in favor of $X$ excitons. Fröhlich and Staginnus ${ }^{6}$ have been able to identify, with the aid of twophoton spectroscopy, excitons related to the lowest $X$ critical point in CsI (with $\mathrm{CsCl}$ structure). Such transitions are forbidden in conventional onephoton spectroscopy because of parity ${ }^{19}$; they become allowed as two-photon transitions, since the parity-selection rule is reversed (initial and final states must have the same symmetry). The twophonon $X$ exciton occurs at $6.25 \mathrm{eV}$ in CsI, between the $\Gamma_{8}^{-} \rightarrow \Gamma_{6}^{+}$and its spin-orbit mate $\left(\Gamma_{6}^{-} \rightarrow \Gamma_{6}^{+}\right)$. The $\Gamma_{8}^{-} \rightarrow \Gamma_{6}^{+}$interband transition is forbidden for two photons, but it becomes weakly allowed when considered as an exciton for $n \geq 2$; as such it has also been observed in two-photon spectroscopy. The two-photon absorption edge is shifted with respect to the one-photon edge by the $n=1-n=2$ exciton energy difference.

The bulk of optical measurements existing in the literature has been performed from the absorption edge up to about $12 \mathrm{eV}$. Measurements up to $35 \mathrm{eV}$ have been reported by Saito et al. ${ }^{30}$ One can see in the $\mathrm{Rb}$ halides at $16 \mathrm{eV}$ the onset of transitions from the outermost $\mathrm{Rb}^{*} 4 p$ shell; in the Cs halides at $13 \mathrm{eV}$ the onset of transitions from the outermost $\mathrm{Cs}^{*} 5 p$ shell: The peaks are, however, imbedded in a continuum due to the higher valence bands; unambiguous assignment to the different initial states is difficult. The identification of the onset of the $\mathrm{Rb}^{*} 4 p$ transition and the $\mathrm{Cs}^{*} 5 p$ transitions at 16 and $13 \mathrm{eV}$ agrees with the known energies for the first excitation of the free ions. ${ }^{31}$ Measurements of transitions from the outermost $\mathrm{Na}^{*} 2 p$ transitions in the $\mathrm{Na}$ halides ${ }^{32}$ and the outermost $\mathrm{Li}^{+} 1 s$ transitions in the $\mathrm{Li}$ halides ${ }^{33}$ also give energies in agreement with the onset of transitions in the free ions, i.e., $32.5 \mathrm{eV}$ for $\mathrm{Na}^{*}$ and $60 \mathrm{eV}$ for $\mathrm{Li}^{*}$. The limitation in the resolution of measurements above $10 \mathrm{eV}$, such as those of Saito et al., ${ }^{30}$ is due to the sources commonly used in these experiments. The source problems become more and more severe the higher the photon energy. The intensity of discharge sources usually decreases with increasing photon energy; the line density of multiline sources becomes smaller. For measurements in the photon energy range above $10 \mathrm{eV}$ the ideal source is the synchrotron radiation from high-energy electron synchrotrons and storage rings. ${ }^{34}$

In this paper we report the absorption spectra of the $\mathrm{Rb}$ and $\mathrm{Cs}$ halides between 50 and $250 \mathrm{eV}$. As shown in Fig. 1, mainly transitions with initial states at the outermost $d$ subshells of $\mathrm{Rb}^{*}, \mathrm{Cs}^{+}$, $\mathrm{Br}^{-}$, and $\mathrm{I}^{-}$are expected in this photon energy range. We have also observed transitions from the $p$ levels of the same shell of $\mathrm{Cs}^{+}$. The samples were thin films vacuum deposited onto thin carbon substrates. It is not possible to obtain single crystals thin enough to perform absorption measurements in this region. While single-crystal measurements would be possible by reflection, the reflectivity of the alkali halides between 50 and $250 \mathrm{eV}$ is too small $(<1 \%)$ to perform accurate measurements. Consequently, reflection corrections can be neglected in transmission work. From our knowledge of the width of the valence excitons in thin films, it is possible to say that the width of the rather broad peaks observed between 50 and $250 \mathrm{eV}$ is not due to crystalline disorder. Absorption measurements should also be more accurate in this region than electron energyloss measurements. The latter become preferable in the neighborhood of the plasma frequency of the valence electrons $(\sim 15 \mathrm{eV})$ because of the small values of the dielectric constant. Energy-loss measurements give essentially the function $1 / \epsilon$. 

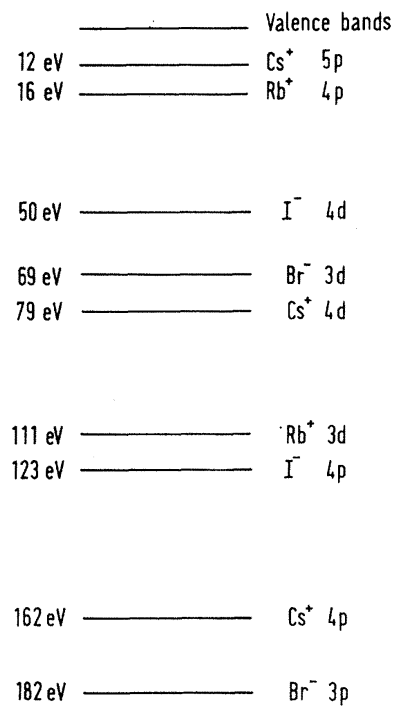

FIG. 1. Schematic diagram of the core energy levels of the $\mathrm{Rb}$ and $\mathrm{Cs}$ halides relevant to our photon energy region. The energies on the left refer to the vacuum level of the free atom.

In Sec. II details of the experimental arrangement are given. Section III gives the results of the measurements. Section IV gives a discussion of the fine structures near threshold as well as a discussion of the characteristic continuum absorption related to the so-called delayed onset of the $d \rightarrow f$ transitions.

\section{EXPERIMENTAL PROCEDURE}

The thin-film absorption measurements were performed using the 7.5-GeV electron synchrotron DESY as the radiation source. ${ }^{35}$ The experimental arrangement is described to some extent elsewhere. ${ }^{36}$ The light coming from the synchrotron passes through a beam pipe of approximately $40-\mathrm{m}$ length and is then focused by a concave mirror into the entrance slit of a grazing incidence monochromator. For the measurements between 50 and $200 \mathrm{eV}$, a gold-coated grating with 2400 lines $/ \mathrm{mm}$ and a blaze angle of $4^{\circ} 16^{\prime}$ was used in first order with an angle of incidence of $12^{\circ} 30^{\prime}$. An Al filter was used to cut off higher spectral orders below $72 \mathrm{eV}$. For the range between 150 and $250 \mathrm{eV}$, a $3600-$ lines $/ \mathrm{mm}$ grating was used with a blaze angle of $3^{\circ} 8^{\prime}$ and an angle of incidence of $3^{\circ} 50^{\prime}$. The wavelength resolution of the instrument was $0.1 \AA$ over the entire energy range. The detector was a Bendix M 306 open magnetic electron multiplier.

The signal from the photomultiplier, placed behind the exit slit, was fed into the $Y$ channel of a $X Y$ potentiometric recorder whose reference sig- nal was proportional to the current in the accelerator, thus compensating for current fluctuations. The $X$ axis of the recorder received a voltage from a potentiometer linked to the wavelength drive of the monochromator. The samples were mounted in front of the focusing mirror. Some samples were prepared by evaporation from $\mathrm{Al}_{2} \mathrm{O}_{3}$-covered molybdenum baskets in situ, while others were prepared ex situ and then transferred to the sample chamber. In situ preparation was especially convenient for the very hygroscopic materials such as RbF and CsF. With both preparation methods the film thickness was determined with an oscillating quartz ${ }^{37}$ calibrated by Tolansky interferometry. The accuracy of the thickness determination is estimated to be about $\pm 20 \%$.

No differences have been found for samples prepared by either procedure, provided the samples deposited ex situ are kept exposed to the atmosphere for only a short time. The substrates were carbon foils $\sim 500 \AA$ thick ${ }^{38}$ supported by a $75-\mu \mathrm{m}$ copper grid. Best results were obtained with samples which transmitted about 10 to $50 \%$ of the incident light. If the samples are too thick, the influence of stray light, higher spectral orders, and pin holes causes errors. Since the absorption coefficient near thresholds of inner-shell transitions and near broad $d \rightarrow f$ peaks are different, samples of different thicknesses, ranging from 100 to $10000 \AA$, had to be used to obtain uniform accuracy. The consistency of the results for samples of different thickness was always checked. All measurements were performed at room temperature.

For measurements of samples evaporated in situ, the transmission of the carbon substrates was measured before the evaporation. With samples evaporated ex situ, the transmission of another similar carbon film was used as reference. The $X Y$ recorder plots were digitalized and computer processed so as to obtain the absorption coefficients shown in Figs. 2-10. The absolute error in the absorption-coefficient curves is about $\pm 20 \%$, mostly due to uncertainties in the sample thickness. The relative consistency of the values in adjacent regions is about $\pm 3 \%$, due mostly to incomplete compensation of synchrotron fluctuations by our recording system.

\section{EXPERIMENTAL RESULTS AND DISCUSSION}

\section{A. General Review of Absorption Curves}

\section{1. $\mathrm{Rb}$ Halides}

Figures 2-5 show the absorption spectra of all $\mathrm{Rb}$ halides in the energy range from $\sim 50$ to $\sim 180$ $\mathrm{eV}$. The onset of $\mathrm{Rb}^{+} 3 d$ transitions (for reasons of convenience we use both the atomic and the $x$-ray 


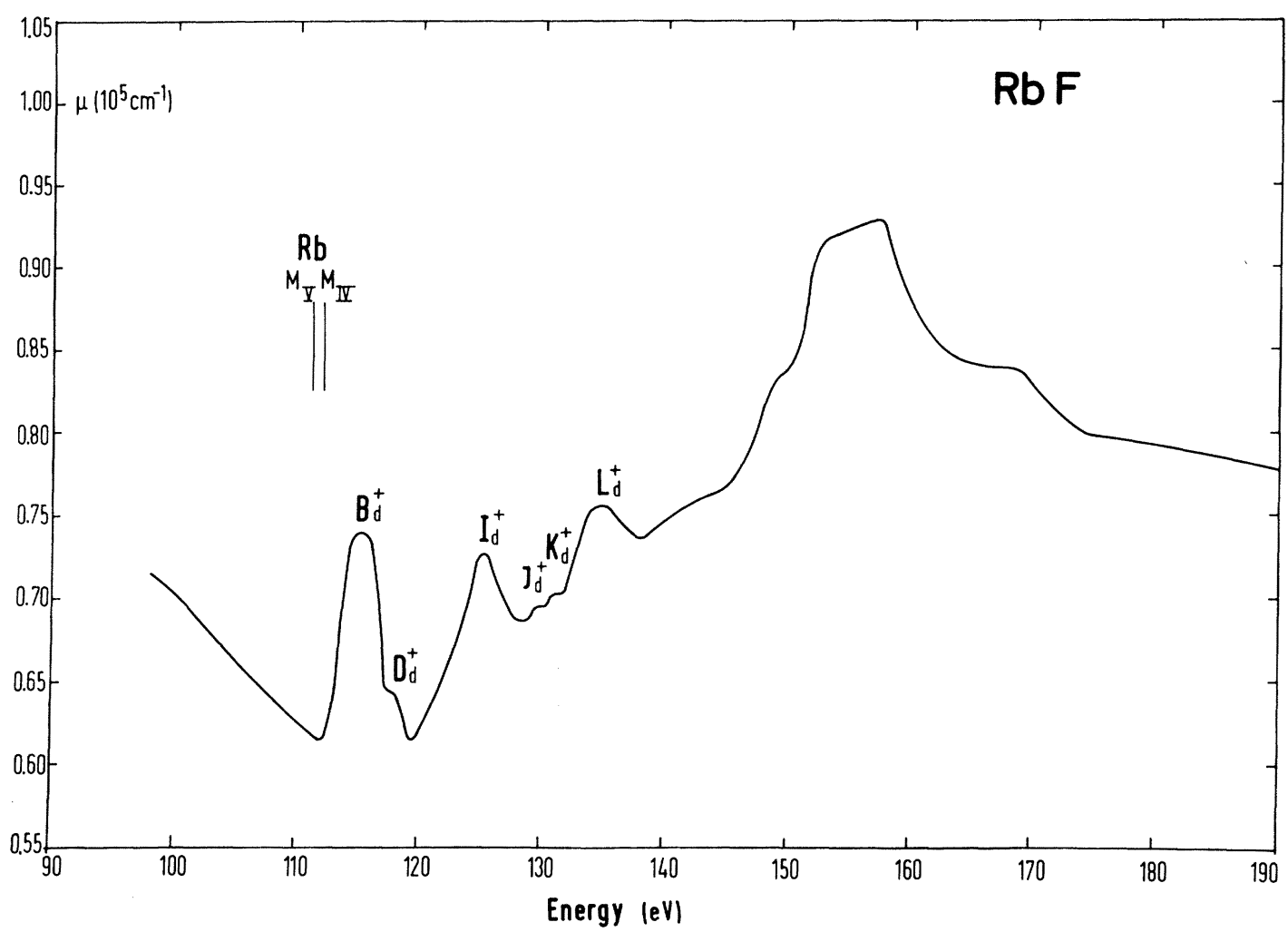

FIG. 2. Absorption spectrum of RbF from 90 to $190 \mathrm{eV}$. All measurements in this and subsequent figures were performed at room temperature.

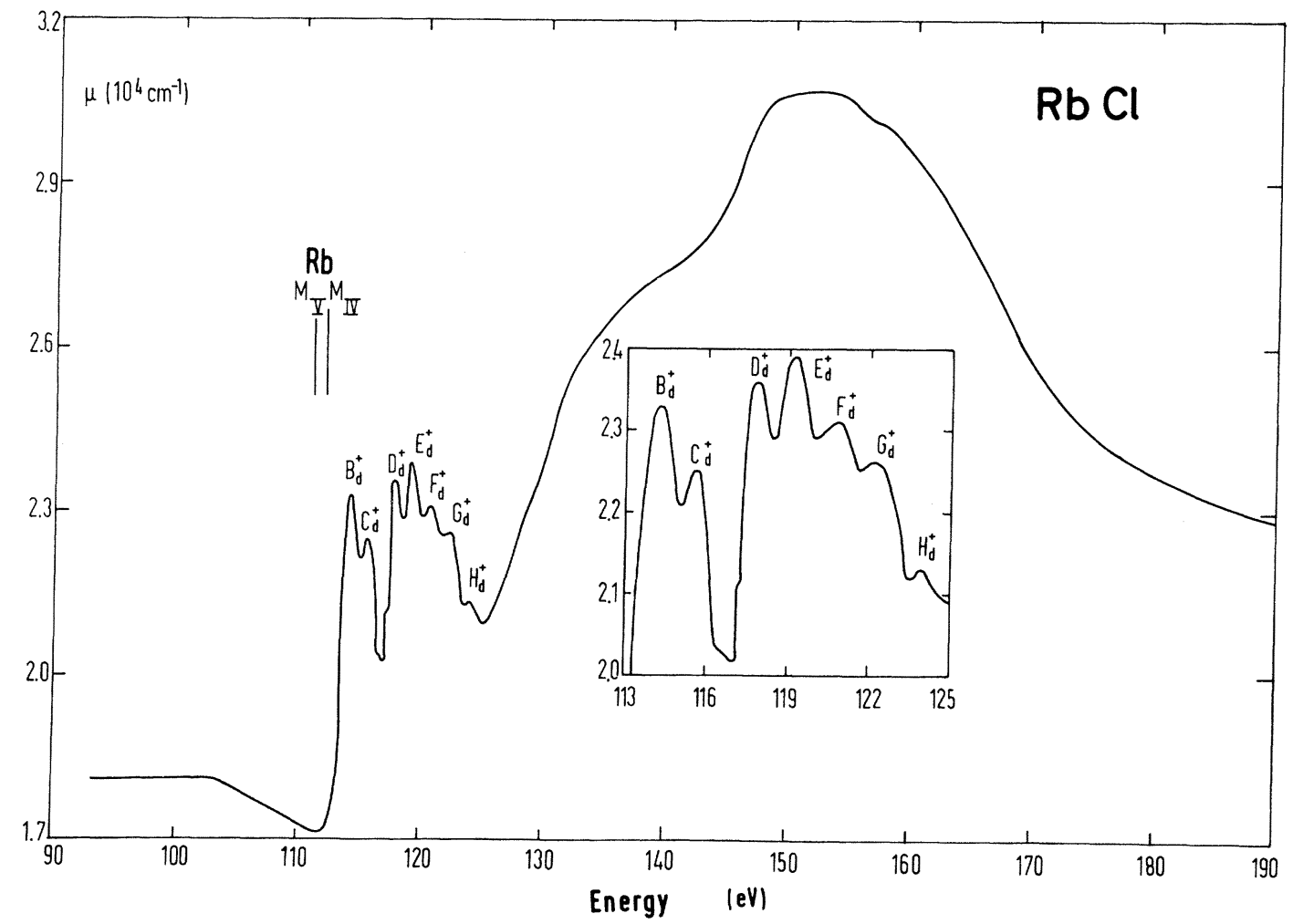

FIG. 3. Absorption spectrum of $\mathrm{RbCl}$ from 90 to $190 \mathrm{eV}$. 


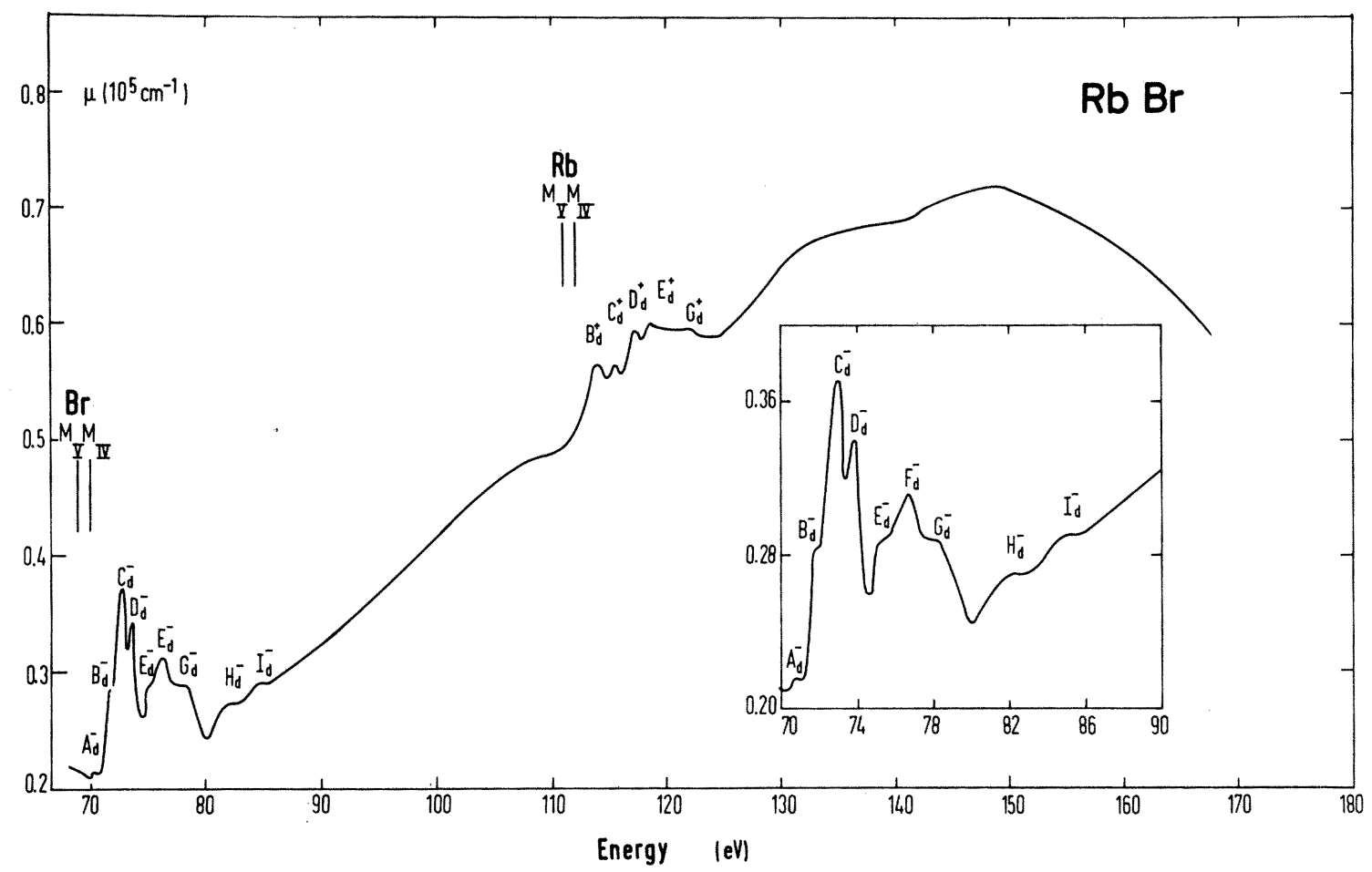

FIG. 4. Absorption spectrum of $\mathrm{RbBr}$ from 70 to $170 \mathrm{eV}$.

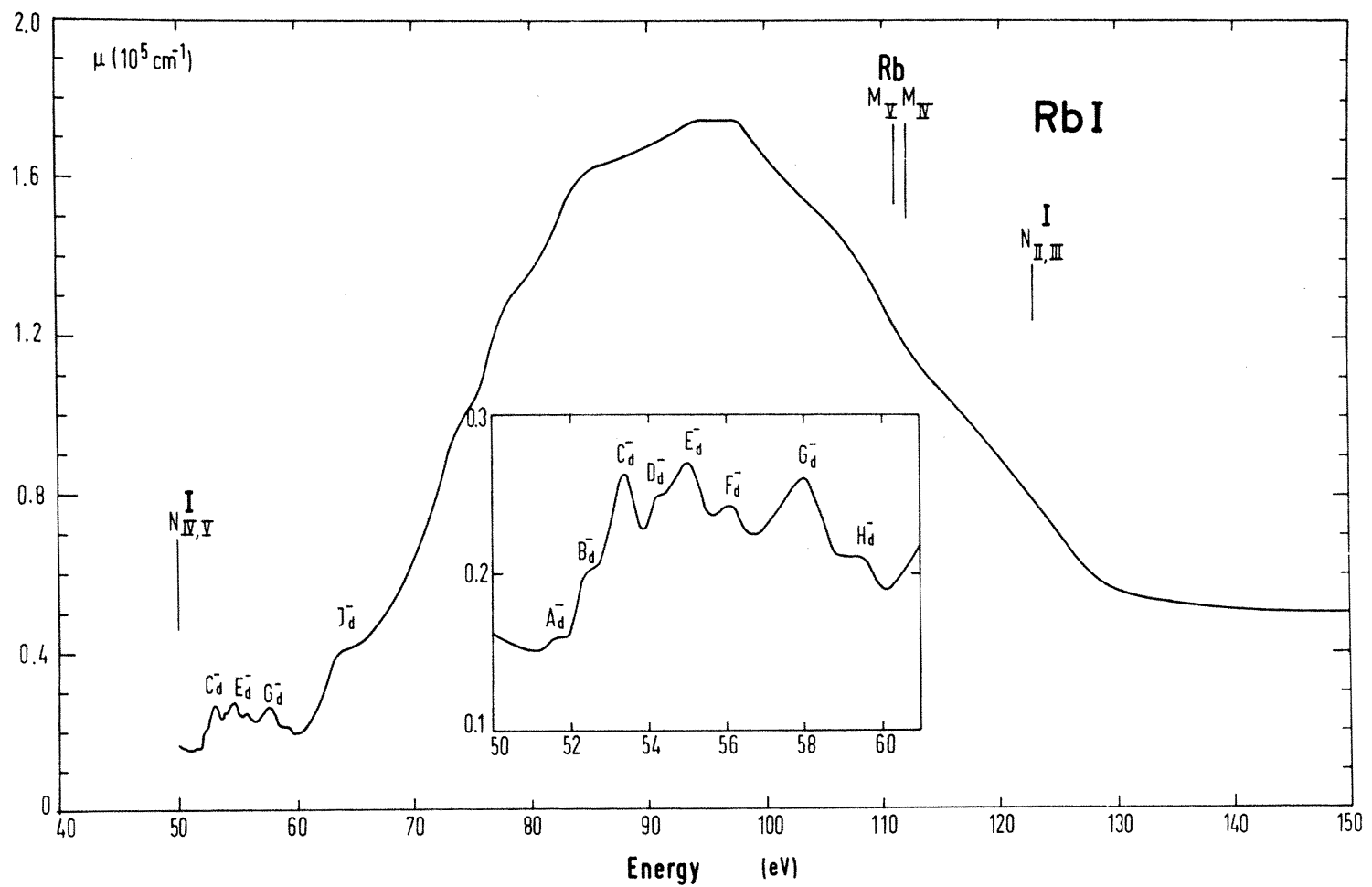

FIG. 5. Absorption spectrum of RbI from 50 to $150 \mathrm{eV}$. 
nomenclature for the different subshells, i.e., $N_{\mathrm{IV}, \mathrm{V}} \sim 4 d, N_{\mathrm{II}, \mathrm{III}} \sim 4 p, M_{\mathrm{IV}, \mathrm{V}} \sim 3 d$, and $\left.M_{\mathrm{II}, \mathrm{III}} \sim 3 p\right)$ can be seen by the appearance of fine structure near $110 \mathrm{eV}$. In $\mathrm{RbF}$ (Fig. 2) and $\mathrm{RbCl}$ (Fig. 3) the fine structure is sitting on an absorption continuum, which must still be due to transitions of outer electrons (valence band, $\mathrm{Rb}^{+} 4 p$ and $4 s$ shells) into higher-energy states of the conduction band.

The additional absorption due to transitions from the $3 d$ shell reaches in the first maxima about $30 \%$ of that in the underlying continuum. The fine-structure region extends over about 20 $\mathrm{eV}$, followed by an increasing absorption continuum with a maximum at about $150 \mathrm{eV}$. At higher energies, the absorption begins to decrease again. This behavior is very similar to what has been found for the $3 d$ transitions of solid $\mathrm{Kr} .{ }^{39}$ This continuous absorption, which follows the fine structure near threshold, can be explained as a delayed onset of $d \rightarrow f$ transitions. ${ }^{40}$ The atomic potential caused by a superposition of the central potential of the core (appropriately screened Coulomb potential) and the centrifugal $l(l+1) / r^{2}$ term in the radial-wave equation gives a potential barrier between bound and free states which suppresses $d \rightarrow f$ transitions near threshold and shifts their oscillator strengths to higher energies. The effect is especially pronounced for the $4 d$ transitions, as we will see later.

In $\mathrm{RbBr}$, the $\mathrm{Rb}^{*} 3 d$ transitions at $110 \mathrm{eV}\left(B_{d}^{+}\right.$, $\left.C_{d}^{+}, \ldots\right)$ are proceeded by the $\mathrm{Br}^{-} 3 d$ transitions $\left(A_{d}^{-}, B_{d}^{-}, \ldots\right)$ which have their threshold at $70 \mathrm{eV}$. Since the $\mathrm{Br}^{-} 3 d$ transitions also have a delayed $d \rightarrow f$ onset, the $\mathrm{Rb}^{+} 3 d$ fine structure takes place on an increasing absorption continuum. It should be noticed, however, that the oscillator strength of the $\mathrm{Rb}^{+} 3 d$ peaks near threshold in $\mathrm{RbBr}$ is not smaller than in $\mathrm{RbCl}\left(\sim 0.5 \times 10^{4} \mathrm{~cm}^{-1}\right)$. The superimposed maxima of the delayed $d \rightarrow f$ transitions of $\mathrm{Br}^{-}$and $\mathrm{Rb}^{+}$are responsible for the broad maxima in the 130 - to $150-\mathrm{eV}$ region.

In $\mathrm{RbI}$, near $50 \mathrm{eV}$ we see the onset of I $4 d$ transitions. The maximum of the $d \rightarrow f$ transitions is at about $95 \mathrm{eV}$ and much stronger $\left(\sim 1.8 \times 10^{5}\right.$ $\mathrm{cm}^{-1}$ ) than for other $\mathrm{Rb}$ halides. If one assumes an oscillator strength of the $\mathrm{Rb}^{+} 3 d$ peaks near threshold similar to that of $\mathrm{RbBr}$ and $\mathrm{RbCl}$, it becomes clear why it should not be detectable any more in the presence of the strong $I^{-}$continuum.

\section{Cs Halides}

The corresponding spectra of the Cs halides are shown in Figs. 6-9. The $\mathrm{Cs}^{+} 4 d$ threshold occurs at about $78 \mathrm{eV}$ and can clearly be seen in CsF (Fig. 6) and $\mathrm{CsCl}$ (Fig. 7). As in the $\mathrm{Rb}$ halides, the fine structure $\left(A_{d}^{+}, B_{d}^{+}, \ldots\right)$ is superimposed on an absorption continuum of outer-shell transitions. For all Cs halides we encounter $4 d$ transitions and, as in Rbl, the continuum absorption above the Cs threshold is very strong $\left(5 \times 10^{5}\right.$ $\mathrm{cm}^{-1}$ ). In CsBr (Fig. 8) we see first the $\mathrm{Br}^{-} 3 d$ structure $\left(B_{d}^{-}, C_{d}^{-}, \ldots\right)$ near $70 \mathrm{eV}$ followed by the $\mathrm{Cs}^{+} 4 d$ structure at $80 \mathrm{eV}$. The absorption continuum of the $3 d$ transitions of $\mathrm{Br}^{-}$does not much influence the $\mathrm{Cs}^{+} 4 d$ absorption, in sharp contrast to CsI (Fig. 9) where the $\mathrm{Cs}^{+} 4 d$ threshold is situated on the I $4 d$ continuum (threshold at $50 \mathrm{eV}$ ). Again the oscillator strength of the additional $\mathrm{Cs}^{+}$ $4 d$ fine structure in CsI is not smaller than in the other Cs halides but more difficult to detect because of the strong $\mathrm{I}^{-}$-continuum absorption on which it is superimposed. On the high-energy side of the $d \rightarrow f$ peak, we see another onset of fine structure due to transitions from the $\mathrm{Cs}^{+} 4 p$ shell $\left(A_{p}^{*}\right)$. Figures 6-9 only cover the spectral range up to $160 \mathrm{eV}$, where the onset of $4 p$ transitions takes place. Details of the $\mathrm{Cs}^{*} 4 p$ structure at higher energies are given in Fig. 10. Measurements of $\mathrm{CsCl}^{41}$ and $\mathrm{CsI}{ }^{42}$ have also been reported by Brown and co-workers. Their results are in good qualitative agreement with ours, although the oscillator strength in the $d \rightarrow f$ maxima near $110 \mathrm{eV}$ are somewhat different. Stray light and higher spectral orders may be responsible for the discrepancy. The presence of stray-light saturation in our results was ruled out by measuring a wide range of sample thicknesses: The spectra obtained for the thinner samples are essentially identical, while thicker samples show spurious saturation in the absorption.

The big oscillator strength in the delayed $d \rightarrow f$ maximum for $4 d$ transitions, and the comparatively smaller one for the $3 d$ transitions, has been discussed by Fano and Cooper. ${ }^{40}$ It is sometimes called a resonance near threshold, which shows up as a concentration of the integrated oscillator strength above threshold; it is particularly strong if $d \rightarrow f$ transitions can take place within the same shell. This is obviously possible for $4 d$ but not for $3 d$ transitions. The strong absorption continuum above threshold is about $80 \mathrm{eV}$ wide for $4 d$ transitions but it is flattened and spread over a region of several hundreds $\mathrm{eV}$ for $3 d$ transitions. To check this more quantitatively we have evaluated $N_{\text {eff }}$, the effective number of electrons whose oscillator strength is exhausted within the energy range covered by our measurements. It can be directly obtained from the absorption curves as

$$
N_{\text {eff }}=2.3 \times 10^{15} a^{3} \int_{E_{1}}^{E_{2}} \mu(E) n(E) d E
$$

(electrons/molecule). 


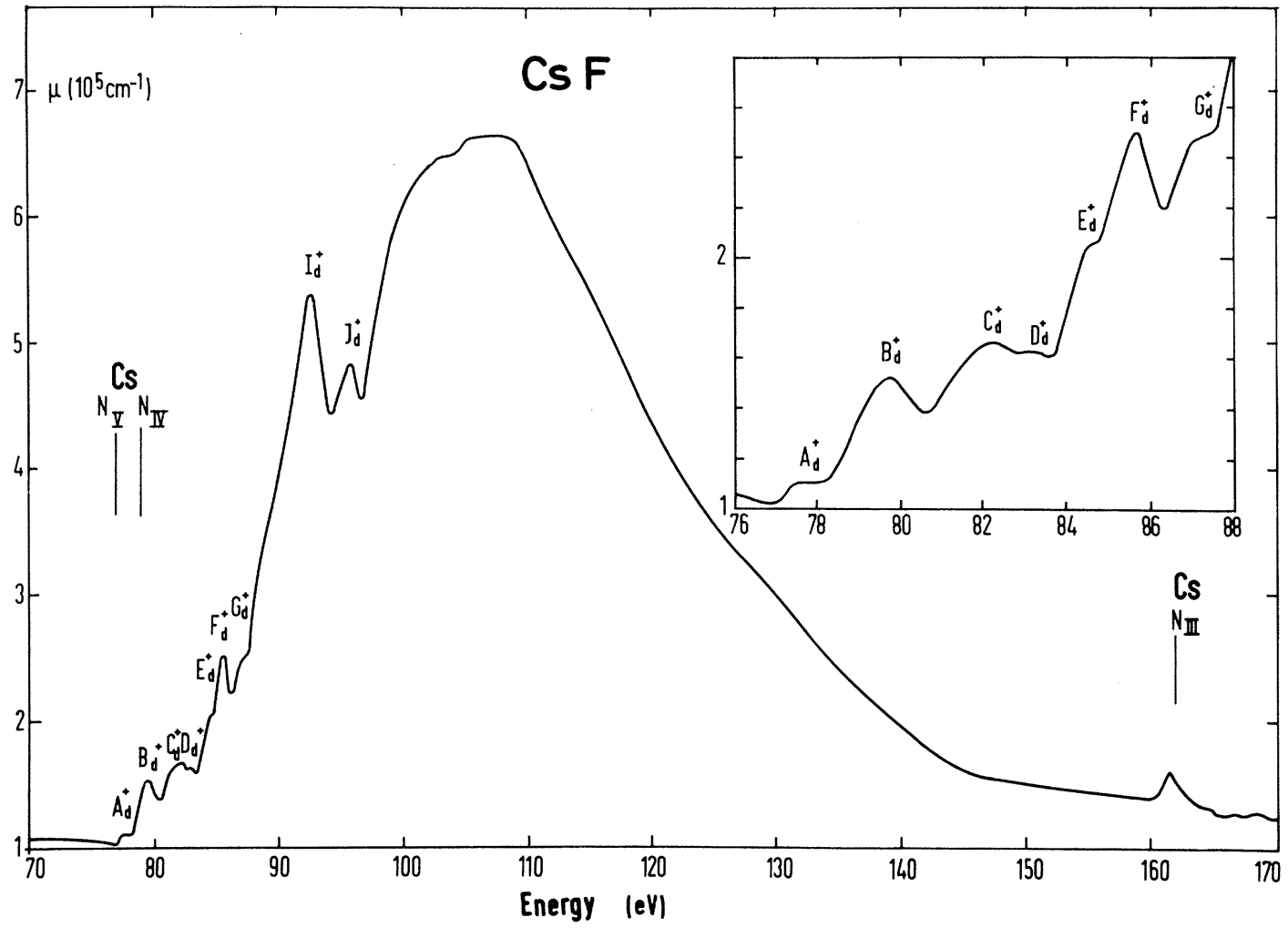

FIG. 6. Absorption spectrum of CsF from 70 to $170 \mathrm{eV}$.

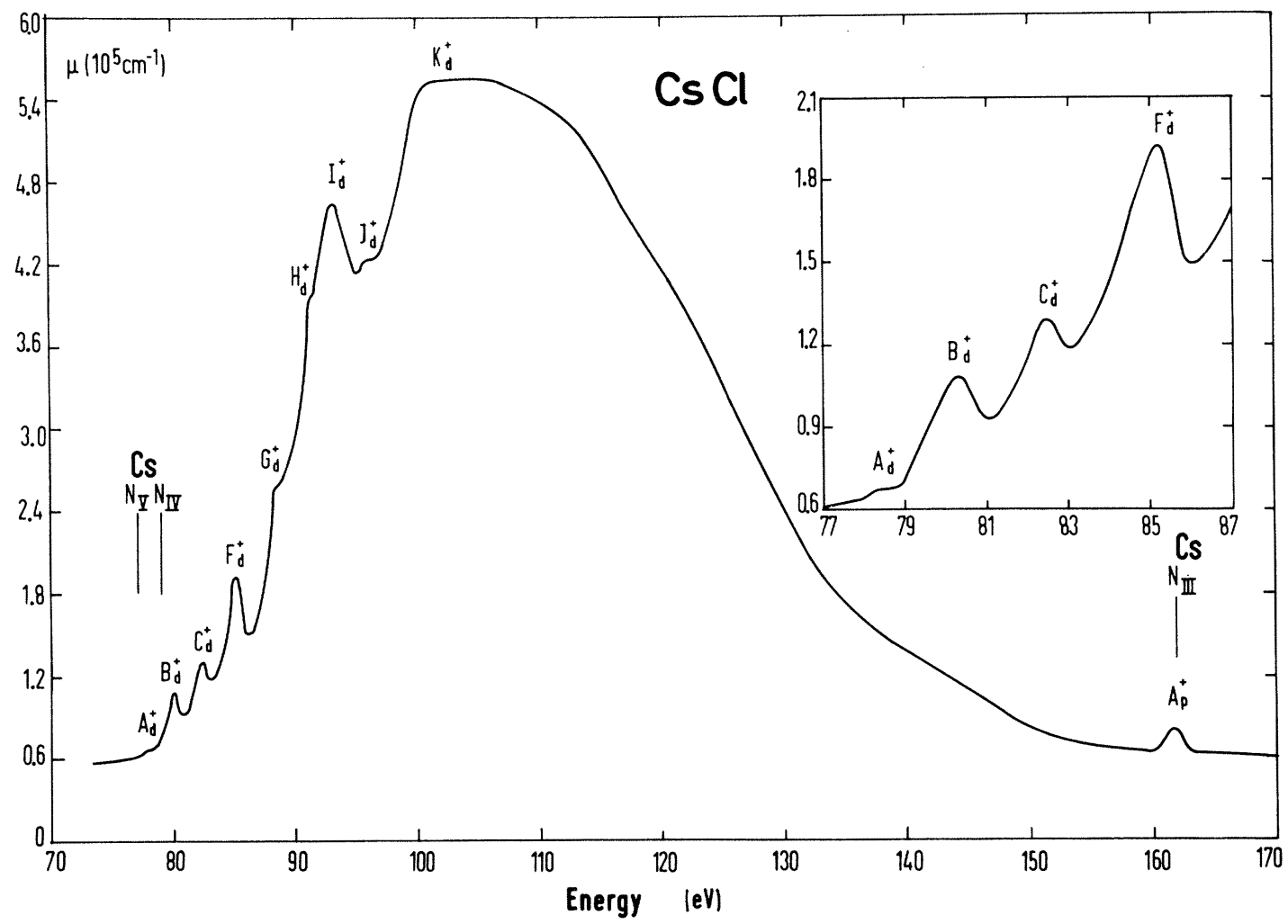

FIG. 7. Absorption spectrum of $\mathrm{CsCl}$ from 70 to $170 \mathrm{eV}$. 


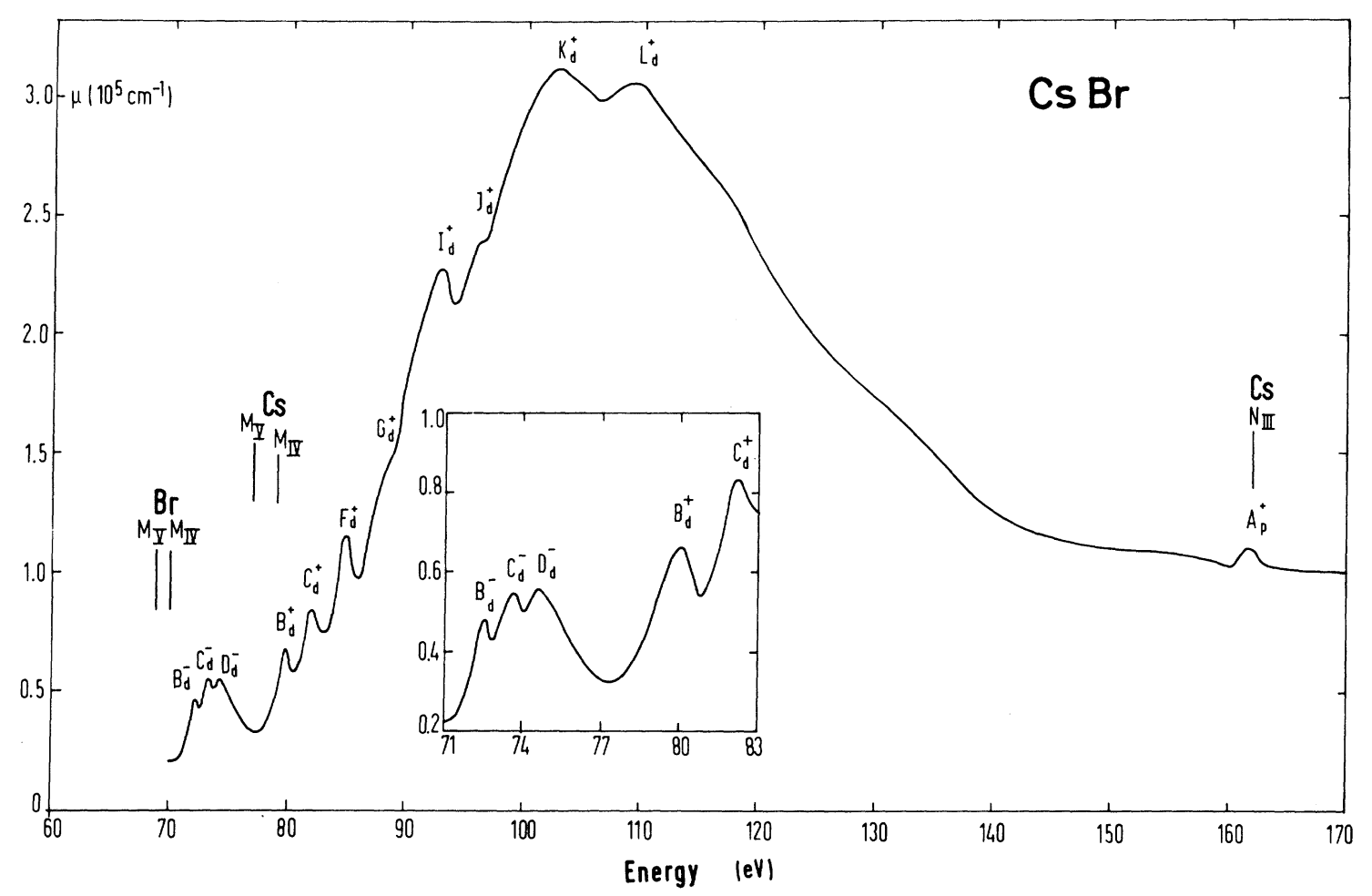

FIG. 8. Absorption spectrum of CsBr from 70 to $170 \mathrm{eV}$.

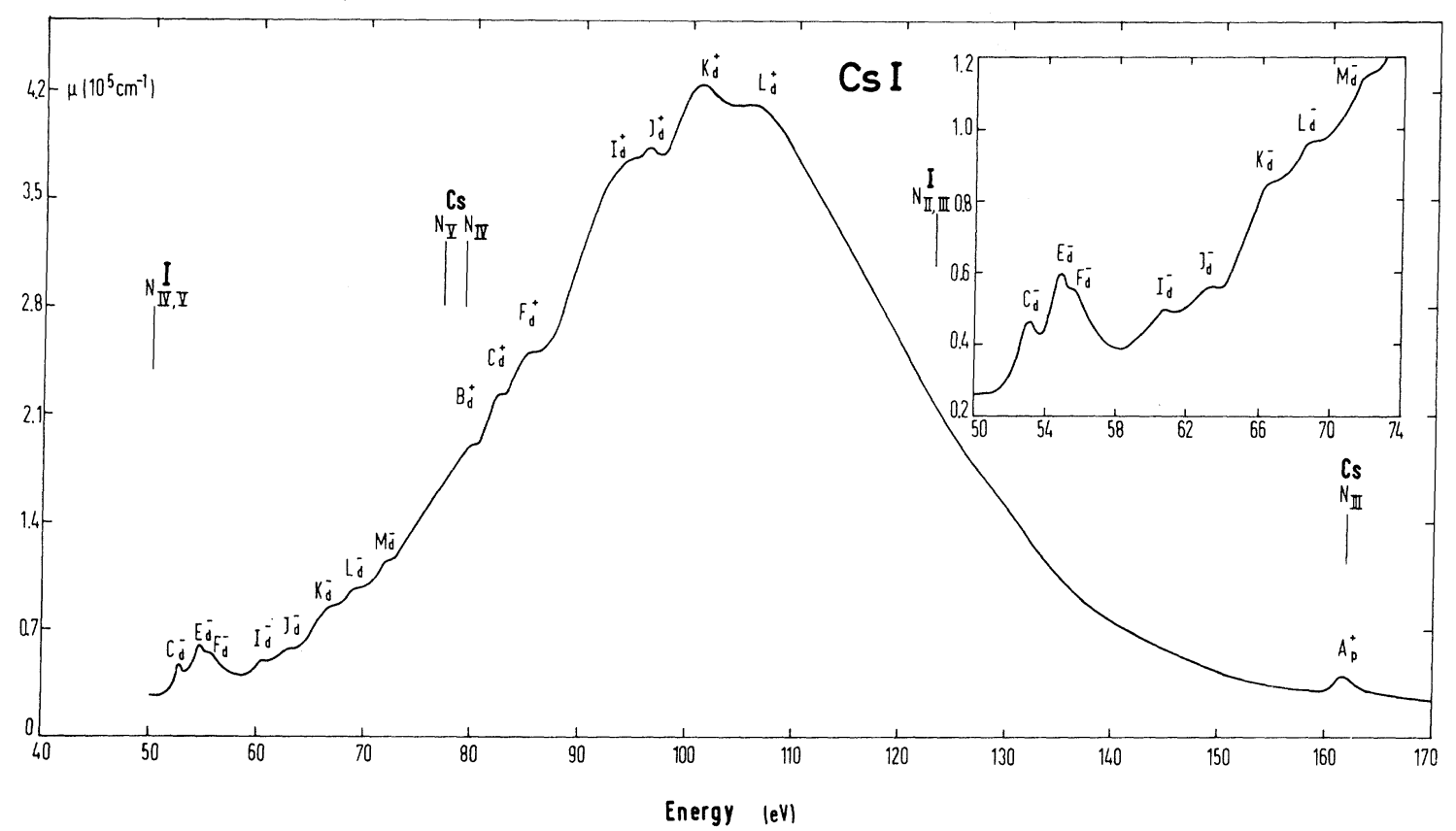

FIG. 9. Absorption spectrum of CsI from 50 to $170 \mathrm{eV}$. 


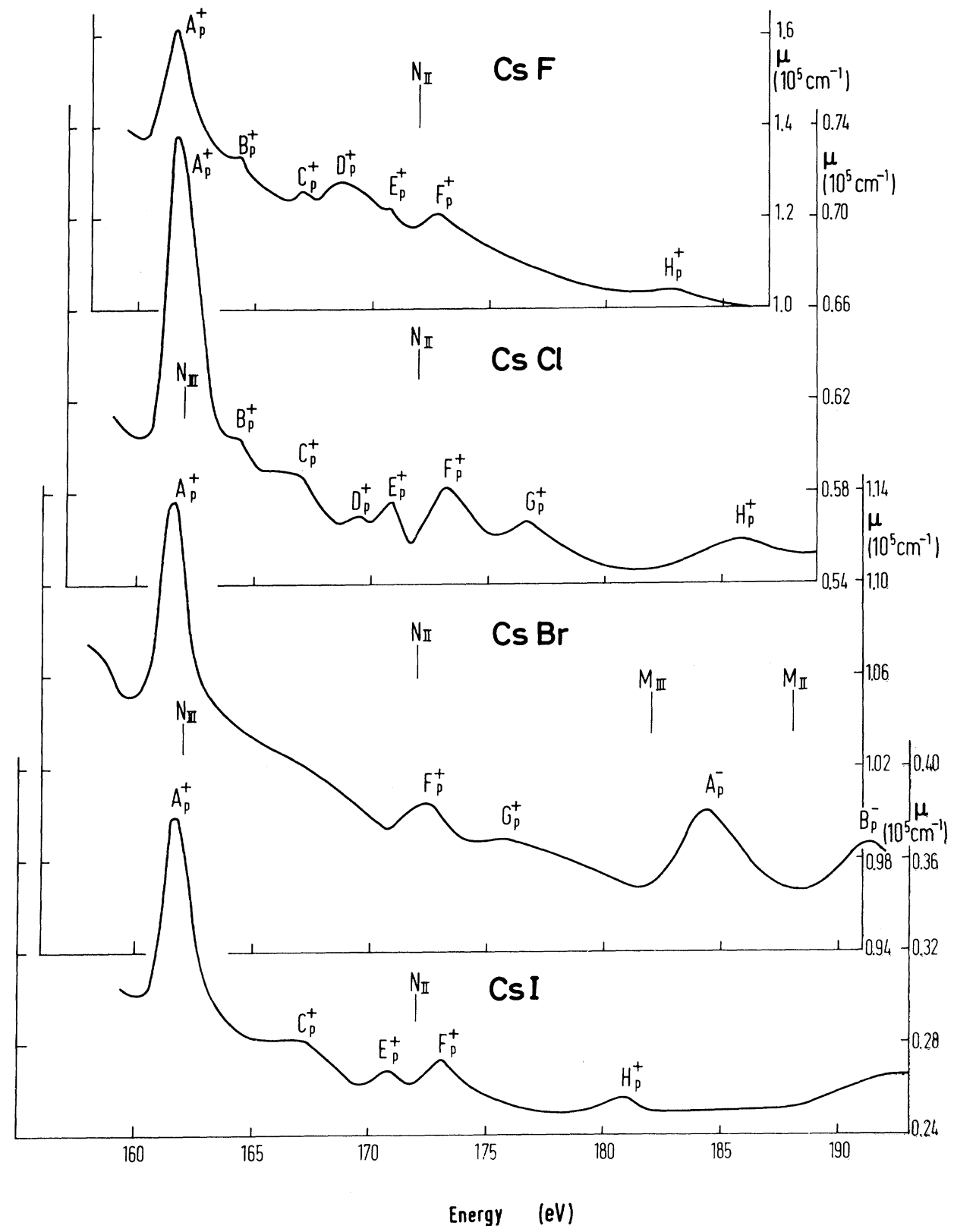

FIG. 10. Absorption spectra of the Cs halides in the region of $\mathrm{Cs}^{+} 4 p$ transitions,

Here, $n$ is the real part of the refractive index, which can be set equal to 1 in our energy region, as will be shown later, and $a$ is the lattice constant. The $N_{\text {eff }}$ for the different materials measured are summarized in Table I. For materials with only $3 d$ transitions $N_{\text {eff }}$ is small (between 1.3 for $\mathrm{RbCl}$ and 3.8 for $\mathrm{RbBr}$ ), and agrees with the values found for solid krypton and for semiconductors ${ }^{43}$ in the same spectral range. RbI, with $4 d$ transitions of $I$ in our spectral range, has a considerably higher value of $N_{\text {eff }}$, indicating that most of the oscillator strength of the $4 d$ electrons is exhausted. The $4 d$ transitions of $\mathrm{Cs}$ seem to give an even higher value of $N_{\text {eff }}$ (around 15 electrons/molecule). The contribution of both $4 d$ transitions of $\mathrm{Cs}$ and $\mathrm{I}$, is reflected in the even higher value of $N_{\text {eff }}$ for CsI $\left(N_{\text {eff }} \approx 18\right)$. Similar results have been found for the $4 d$ transitions of $\mathrm{Xe}$ and of compound semiconductors. ${ }^{43}$

The coarse spectral dependence of the contribution of the transitions under consideration to the real part of the refractive index $(\Delta n)$, as obtained from the Kramers-Kronig analysis of the data of Figs. 2-9, is represented in Table II. The con- 
TABLE I. Number of effective electrons $N_{\text {eff }}$ obtained from our experimental absorption spectra with Eq. (1) for the $\mathrm{Rb}$ and $\mathrm{Cs}$ halides. The range of integration $\left(E_{1}-E_{2}\right)$ varies slightly for the various materials and is also listed.

\begin{tabular}{lrrr}
\hline \hline Material & $E_{1}$ & $E_{2}$ & $N_{\text {eff }}$ \\
\hline $\mathrm{RbF}$ & 100 & 190 & 2.8 \\
$\mathrm{RbCl}$ & 100 & 190 & 1.3 \\
$\mathrm{BrBr}$ & 70 & 170 & 3.8 \\
$\mathrm{RbI}$ & 50 & 150 & 8.3 \\
$\mathrm{CsF}$ & 70 & 190 & 16.2 \\
$\mathrm{CsCl}$ & 70 & 190 & 15.1 \\
$\mathrm{CsBr}$ & 70 & 190 & 13.1 \\
$\mathrm{CsI}$ & 50 & 190 & 18 \\
\hline \hline
\end{tabular}

tribution of transitions below $50 \mathrm{eV}$ can be estimated with the standard free-electron expression $\left(n^{2}=1-\omega_{p}^{2} / \omega^{2}\right)$; it is also small. As suggested earlier, $n$ can be taken equal to 1 for the purpose of evaluating Eq. (1).

\section{B. Fine Structure of Rb Halides}

\section{1. $\mathrm{Rb}^{+} 3 d$ Transitions}

The transitions from the $\mathrm{Rb}^{+} 3 d$ subshell, which have their onset at about $110 \mathrm{eV}$, exhibit considerable fine structure [shown in Fig. 2 as for $\mathrm{RbF}$, Fig. 3 for $\mathrm{RbCl}$, and Fig. 4 for $\mathrm{RbBr}$ and labeled $B_{d}^{+}, C_{d}^{+}, \ldots$. The positions of these peaks are listed in Table III. The corresponding spin-orbit splitting can be estimated to be $1.67 \mathrm{eV}$ by interpolation between the values calculated by Herman and Skillman for $\mathrm{Kr}(1.4 \mathrm{eV})$ and $\mathrm{Sr}(1.96 \mathrm{eV}){ }^{44}$ The actual value of the $3 d$ spin-orbit splitting of $\mathrm{Rb}$ may actually be smaller. The value experimentally determined for gaseous $\mathrm{Kr}$ by Codling and Madden ${ }^{45}$ is $1.22 \mathrm{eV}$, which is $0.18 \mathrm{eV}$ smaller than the calculated one. We shall therefore reduce the calculated spin-orbit splitting of $R b$ by 0.18 $\mathrm{eV}$, thus obtaining an estimate of $1.5 \mathrm{eV}$. An inspection of the peak positions listed in Table III suggests that the pairs $\left(B_{d}^{+}, C_{d}^{+}\right),\left(D_{d}^{+}, E_{d}^{*}\right)$, and perhaps $\left(F_{d}^{*}, G d^{+}\right)$, with a separation of about 1.5 $\mathrm{eV}$, are spin-orbit mates. The same conclusion applies to the $\left(B_{d}^{+}, C_{d}^{+}\right)$and $\left(D_{d}^{+}, E_{d}^{+}\right)$pairs of $\mathrm{RbBr}$. In $\mathrm{RbF}$ the peaks observed are much broader ( $3 \mathrm{eV}$ width) than for $\mathrm{RbCl}$ and $\mathrm{RbBr}$ and hence the spin-orbit structure is not resolved. The reason for the larger width in $\mathrm{RbF}$ is not clear, but it may be related to a greater amount of crystalline disorder associated with the higher melting point of the material $\left(775^{\circ} \mathrm{C}\right.$ for $\mathrm{RbF}, 715^{\circ} \mathrm{C}$ for $\mathrm{RbCl}, 682^{\circ} \mathrm{C}$ for $\mathrm{RbBr}, 642^{\circ} \mathrm{C}$ for $\mathrm{RbI}{ }^{46}$; the substrates were kept at room temperature during the evaporation) or with the highly hygroscopic char- acter of RbF. No structure related to the $R b 3 d$ levels has been observed in the $110-120-\mathrm{eV}$ region for RbI. This fact is undoubtedly due to the strength of the $\mathrm{I}^{-} 4 d$ continuum. The strength of the $\mathrm{Rb} 3 d$ transitions should be weak with respect to the continuum and, at the same time, their linewidth should be large because the $\mathrm{Rb} 3 d$ transitions must occur at the high-energy side of the maximum in the continuum. This last fact provides a decay channel with a high density of states.

While the identification of spin-orbit mates given above is rather plausible, any further steps towards interpreting the fine structure of Figs. 2-5 must be taken, at present, on rather shaky grounds. The first question that one must consider is whether the structure can be interpreted in terms of one-electron band theory (density of conduction states $\times$ oscillator strength) or whether it is necessary to invoke many-body effects such as exciton interaction. It is known that final-state Coulomb interaction between excited electron and hole left behind can play an important role in determining the absorption structure caused by valence electrons, especially at the fundamental edge but also at higher energies. ${ }^{47,48}$ In the case of metals, such interaction is responsible for the sharp structure observed for transitions from core levels to the Fermi surface. ${ }^{49}$

The width of the lines shown in Figs. 2-5 (the same conclusion applies to fine structure discussed later) is of the order of the width of structure in the one-electron density of states $(\sim 1 \mathrm{eV}),{ }^{50}$ and hence it is highly questionable whether the exciton interaction plays a significant role in determining the experimental spectra. Unfortunately, whereas a large number of band-structure calculations have been performed for the alkali halides, ${ }^{15-20}$ the density of states - let alone matrix elements for core transitions - have yet to appear. A comparison of such calculations with the experimental data should solve the question of the significance of exciton interaction in determining the line shapes. We should point out that Klima ${ }^{50}$ has calculated $\mathrm{x}$-ray emission spectra for $\mathrm{Si}(1 s, 2 p)$ and $\mathrm{Ge}(1 s, 2 p, 3 p)$ and found good agreement with experiments. Evidence of excitonic effects has been obtained in $\mathrm{NaCl}$ from energy distribution measurements of photoemitted electrons excited from the $\mathrm{Na}^{+} 2 p$ shell. ${ }^{51}$

We shall make a crude attempt, however speculative, to assign observed structure to critical points in the calculated conduction bands. Such an assignment would remain valid in the presence of exciton interaction, provided such interaction does not completely scramble the calculated bands and one can still talk of excitons "tied" to certain interband critical points. Our work can be put on 
TABLE II. Contribution to the core transitions discussed in this paper to the refractive index of the $R b$ and Cs halides.

\begin{tabular}{|c|c|c|c|c|c|c|c|c|}
\hline \multirow{2}{*}{$\begin{array}{c}\text { Photon energy } \\
(\mathrm{eV})\end{array}$} & \multicolumn{8}{|c|}{$\Delta_{n} \times 10^{2}$} \\
\hline & $\mathrm{RbF}$ & $\mathrm{RbCl}$ & $\mathrm{Rb} \mathrm{Br}$ & $\mathrm{RbI}$ & $\mathrm{CsF}$ & $\mathrm{CsCl}$ & $\mathrm{CsBr}$ & C'sl \\
\hline 60 & & & & 1.3 & & & & 2.3 \\
\hline 70 & & & & 1.5 & & & & 2.6 \\
\hline 80 & & & 0.3 & 1.0 & 4.0 & 3.7 & 2.2 & 2.5 \\
\hline 90 & & & 0.3 & 0.2 & 4.5 & 3.9 & 2.2 & 1.8 \\
\hline 100 & & 0.2 & 0.3 & -0.4 & 2.2 & 1.8 & 1.2 & 0.2 \\
\hline 110 & 0.3 & 0.1 & 0.2 & -0.8 & -1.0 & -0.7 & -0.2 & -1.4 \\
\hline 120 & 0.2 & 0.1 & 0.1 & -0.7 & -2.3 & -2.1 & -0.9 & -2.0 \\
\hline 130 & 0.1 & 0.1 & 0.0 & -0.6 & -2.3 & -2.4 & -0.9 & -1.9 \\
\hline 140 & 0.1 & 0.0 & -0.1 & & -2.0 & -1.9 & -0.8 & -1.5 \\
\hline 150 & 0.0 & 0.0 & -0.2 & & -1.6 & -1.5 & -0.7 & -1.2 \\
\hline 160 & -0.2 & -0.1 & -0.3 & & -1.4 & -1.2 & -0.6 & -0.9 \\
\hline 170 & -0.2 & -0.1 & & & -1.3 & -1.0 & -0.6 & -0.8 \\
\hline 180 & & & & & & -0.9 & -0.6 & -0.6 \\
\hline
\end{tabular}

slightly firmer grounds by taking into account the ionic composition of the wave functions of the various band states, given by Onodero, Okazaki, and Inui ${ }^{52}$ for $\mathrm{KI}$ and by Onoder $\mathrm{o}^{19}$ for CsI. (It is reasonable to assume that it does not vary much for materials of the same structure.)

For this purpose we show in Fig. 11 the band structure of $\mathrm{RbBr}$ calculated by Kunz. ${ }^{16}$ The bottom of the conduction band, having $s$ character, should not give significant interband structure for transitions from $d$ levels. One may expect, at most, a weak forbidden exciton if the Coulomb interaction mixes a significant amount of $p$-like wave functions. ${ }^{39}$ Such a forbidden exciton is not

TABLE III. Energy (in eV) of the peaks observed in the absorption spectra of the Rb halides at room temperature. The energy of the corresponding free-atom levels referred to vacuum is also given [K. Siegbahn, C. Nordling, A. Fahlman, R. Nordberg, K. Hamrin, H. Hedman, G. Johansson, T. Bergmark, S. -E. Karlsson, I. Linguen, and B. Lindberg, ESCA, Atomic, Molecular, and Solid-State Structure by Means of Electron Spectroscopy (Almquist Wiksells, Uppsala, 1967), Appendix I].

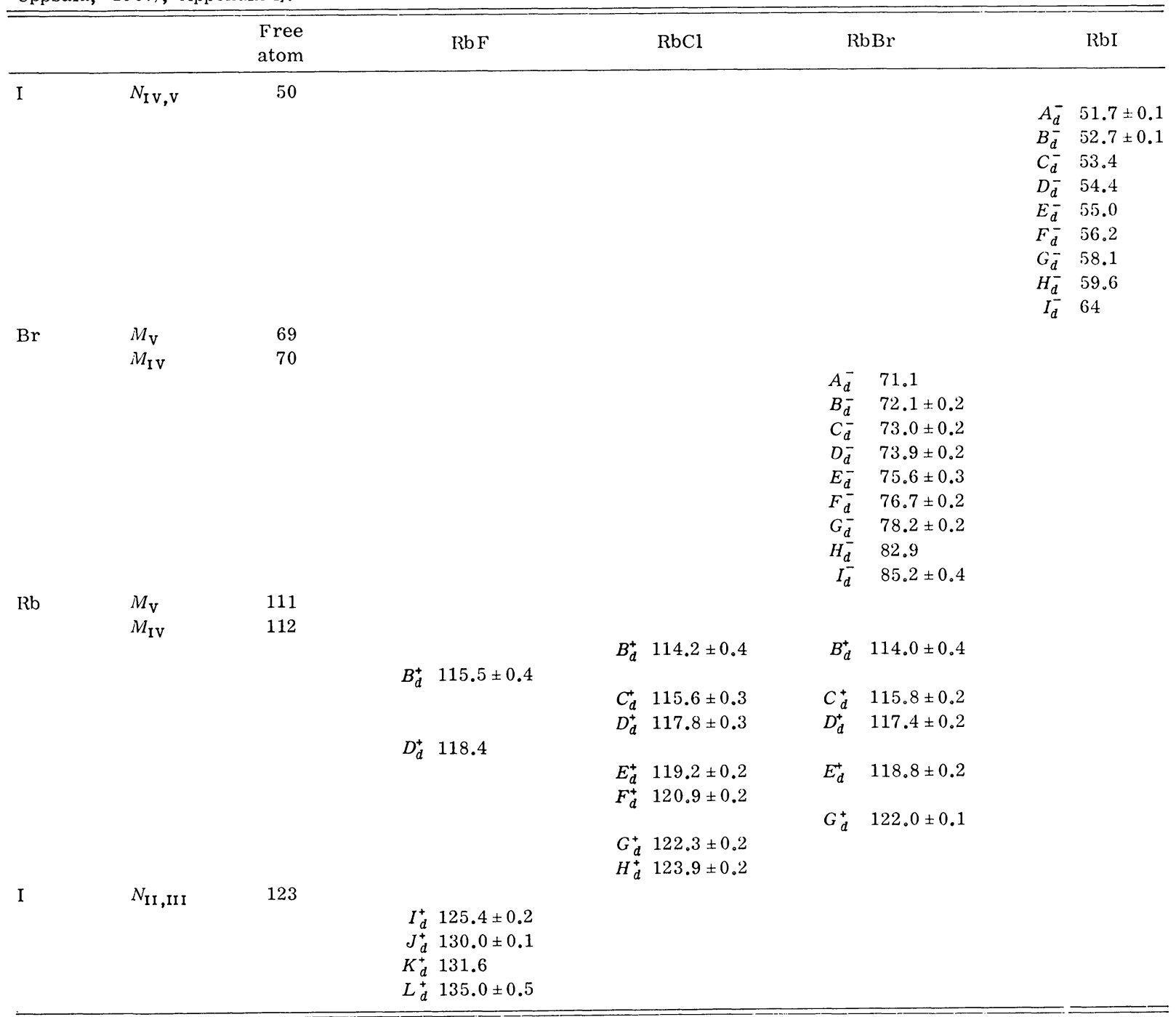




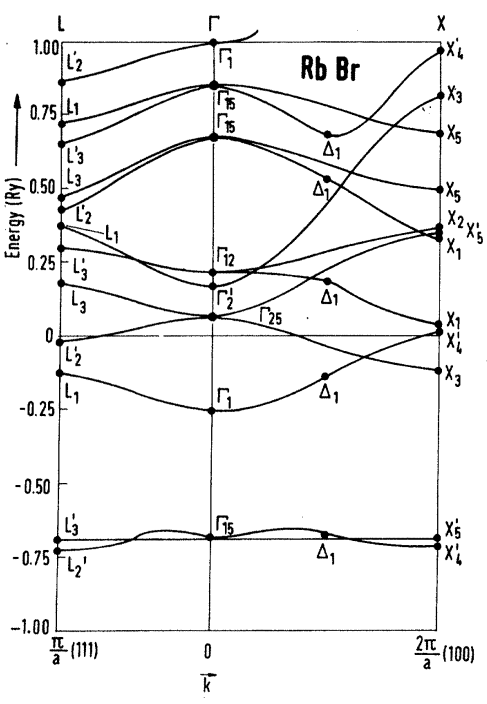

FIG. 11. Band structure of $\mathrm{RbBr}$ according to Kunz (see Ref. 16).

seen for the Rb $3 d$ structure but it may be the weak $A_{d}$ peak discussed latter for $\mathrm{Cs}$, and $\mathrm{Br}$, and $\mathrm{I}$.

Figures 3 and 4 show two well-defined groups of peaks associated with the $\mathrm{Rb}^{+} 3 d$ structure, $\left(B_{d}^{+}, C_{d}^{+}\right)$and $\left(D_{d}^{+}, E_{d}^{+}, F_{d}^{+}\right)$. The separation between the centers of mass of both groups is about $4 \mathrm{eV}$, equal to the separation between the $X_{4}^{\prime}$ and $X_{5}^{\prime}$ states of Fig. 11. These states are composed of an admixture of $p$-wave functions of both constituent atoms, with a slight predominance of the metallic component. Hence it is not unreasonable to assign the two groups of structure to these conduction states or to averages of the bands around these states produced by exciton interaction.

\section{Transitions from Halogen Ion}

Fine structure, obviously related to the $\mathrm{Br}^{-} 3 d$ levels, is seen in Fig. 4 between 70 and $80 \mathrm{eV}$. This structure is very similar to that observed for $\mathrm{KBr} .{ }^{41}$ While Fig. 5 does not show any $\mathrm{Rb}^{+}-$ related structure, it shows structure related to the $4 d$ levels of $\mathrm{I}^{-}$between 50 and $60 \mathrm{eV}$. This structure also has a striking similarity with that reported for KI. ${ }^{41}$ As usual, we dispose first of the relatively simple question of the spin-orbit splitting. The spin-orbit splitting of the $4 d$ levels of I, derived by interpolation between the calculated values ${ }^{44}$ for $\mathrm{Xe}(2.15 \mathrm{eV})$ and $\mathrm{Te}(1.59 \mathrm{eV})$ is $1.87 \mathrm{eV}$. We lower this value to $1.7 \mathrm{eV}$ because of the discrepancy between the calculated and the experimental $(1.93 \mathrm{eV})$ splitting of Xe. ${ }^{45}$ Similar procedure yields a splitting of about 1.0 $\mathrm{eV}$ for the $3 d$ levels of $\mathrm{Br}^{-}$. We thus find plausible the identification of the pairs $\left(A_{d}^{-}, B_{d}^{-}\right)$,
$\left(C_{d}^{-}, D_{d}^{-}\right)$, and $\left(E_{\bar{d}}^{-}, F_{\bar{d}}^{-}\right)$of $\mathrm{RbBr}$ and $\left(B_{d}^{-}, D_{\bar{d}}^{-}\right)$, $\left(C_{d}^{-}, E_{d}^{-}\right)$, and $\left(G_{d}^{-}, H_{d}^{-}\right)$of RbI as spin-orbit mates. The weak $\left(A_{d}^{-}, B_{d}^{-}\right)$pair of $\mathrm{RbBr}$ and the $A_{d}^{-}$line of $\mathrm{RbI}$ are suggestive of a forbidden exciton tied to the $\Gamma_{1}$ conduction-band minimum. The stronger structure in Fig. 4 between 70 and $80 \mathrm{eV}$ can also be subdivided into two groups: $\left(C_{\bar{d}}^{-}, D_{d}^{-}\right)$and $\left(E_{d}^{-}, F_{d}^{-}, G_{d}^{-}\right)$, with a separation of about $4 \mathrm{eV}$. This fact is also suggestive of an origin related to the $X_{4}^{\prime}-X_{5}^{\prime}$ states of Fig. 11. Similar identification, while not so clear, is also possible in Fig. 5.

We have already mentioned the similarity of the $\mathrm{Br}^{-} 3 d$ and $\mathrm{I}^{-} 4 d$ peaks of $\mathrm{Rb}$ and $\mathrm{K}$ halides. $\mathrm{A}$ close similarity also appears in the conductionband structures calculated for $\mathrm{KBr}$ and $\mathrm{RbBr},{ }^{16}$ $\mathrm{KCl}{ }^{53}$ and $\mathrm{RbCl},{ }^{16} \mathrm{KF}$ and $\mathrm{RbF},{ }^{15}$ and, to a lesser extent, KI and RbI. ${ }^{17}$ The conduction-band structures of the corresponding $\mathrm{Na}$ and $\mathrm{Li}$ halides are considerably different. ${ }^{15,16,53-55}$ Such differences must be due, at least in part, to the absence of $d$ states in the cores of $\mathrm{Na}$ and $\mathrm{Li}$, which affects the orthogonalization of the $d$-like conduction electrons. Those similarities also appear in the $\mathrm{Cl}^{-}$ $2 p$ transitions of $\mathrm{KCl}$ and $\mathrm{RbCl}$ (at about $200 \mathrm{eV})^{56}$ and in the $\mathrm{F}^{-} 1 s$ transitions of $\mathrm{KF}$ and $\mathrm{RbF}$ (at about $680 \mathrm{eV})^{57}$; the corresponding spectra of the $\mathrm{Li}, \mathrm{Na}$, and $\mathrm{Cs}$ halides are quite different. The differences in the Cs halides may be attributed, except for CsF, to the different crystal structure. A close similarity in the spectra of the $\mathrm{K}$ and $\mathrm{Rb}$ halides also appears for the valence-band transitions. $^{9}$

\section{Fine Structure of Cs Halides}

The fine structure of the $4 d$ spectra of the Cs halides is shown in Figs. 6-9 and their inserts. Fine structure of the $3 p$ transitions of $\mathrm{Cs}^{+}$is shown in Fig. 10.

\section{1. $\mathrm{Cs}^{+} 4 d$ Transitions}

The transitions from the $\mathrm{Cs}^{*} 4 d$ subshell shown in Figs. 6-9 have their onset at approximately $80 \mathrm{eV}$. This structure shows less detail than the $\mathrm{Rb}^{+} 3 d$ transitions, probably because of the stronger related $d \rightarrow f$ continuum of $\mathrm{Cs}^{+}$. Three strong peaks $\left(B_{d}^{+}, C_{d}^{+}, F_{d}^{+}\right)$are seen, together with a certain amount of weaker structure. For a tabulation of the peak energies, see Table IV. With the usual procedure, we estimate the spinorbit splitting of the $\mathrm{Cs}^{+} 4 d$ levels to be $2.3 \mathrm{eV}$. Hence the $B_{d}^{+}, C_{d}^{+}$pair of $\mathrm{CsF}(2.7 \mathrm{eV}), \mathrm{CsCl}$ (2. $2 \mathrm{eV}), \mathrm{CsBr}(2.1 \mathrm{eV})$, and CsI $(2.1 \mathrm{eV})$ can be identified as spin-orbit mates. A mate for the $F_{d}^{*}$ peak cannot be found unambiguously. The splitting between the $B_{d}^{+}$and $F_{d}^{+}$peak may be susceptible of an interpretation similar to that given for the $\mathrm{Rb}^{+} 3 d$ peaks but not enough information 
TABLE IV. Energy (in eV) of the peaks observed in the absorption spectra of the Cs halides at room temperature.

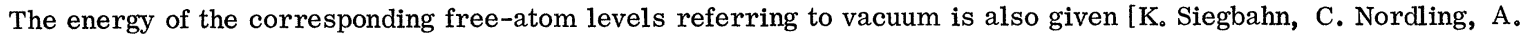
Fahlman, R. Nordberg, K. Hamrin, H. Hedman, G. Johansson, T. Bergmark, S. -E. Karlsson, I. Linguen, and B. Lindberg, ESCA, Atomic, Molecular, and Solid-State Structure by Means of Electron Spectroscopy (Almquist Wiksells, Uppsala, 1967), Appendix I].

\begin{tabular}{|c|c|c|c|c|c|c|c|c|c|}
\hline & & $\begin{array}{l}\text { Free } \\
\text { atom }\end{array}$ & & $\mathrm{CsF}$ & $\mathrm{CsCl}$ & & $\mathrm{CsBr}$ & & CsI \\
\hline \multirow[t]{9}{*}{ I } & $N_{\text {IV }, \mathrm{V}}$ & 50 & & & & & & & \\
\hline & & & & & & & & $C_{d}^{-}$ & $53.1 \pm 0.2$ \\
\hline & & & & & & & & $E_{d}^{-}$ & $54.9 \pm 0.3$ \\
\hline & & & & & & & & $F_{d}^{-}$ & $55.7 \pm 0.1$ \\
\hline & & & & & & & & $I_{d}^{-}$ & $60.8 \pm 0.4$ \\
\hline & & & & & & & & $J_{d}^{\sigma}$ & $63.4 \pm 0.3$ \\
\hline & & & & & & & & $K_{d}^{-}$ & $66.4 \pm 0.5$ \\
\hline & & & & & & & & $L_{d}^{-}$ & $68.5 \pm 0.3$ \\
\hline & & & & & & & & $M_{\bar{d}}^{-}$ & $71.8 \pm 0.5$ \\
\hline \multirow[t]{5}{*}{$\mathrm{Br}$} & $M_{\mathrm{V}}$ & 69 & & & & & & & \\
\hline & $M_{\mathrm{IV}}$ & 70 & & & & & & & \\
\hline & & & & & & $B_{d}^{-}$ & $72.6 \pm 0.1$ & & \\
\hline & & & & & & $C_{d}^{-}$ & $73.7 \pm 0.1$ & & \\
\hline & & & & & & $D_{\bar{d}}^{-}$ & $74.6 \pm 0.1$ & & \\
\hline \multirow{13}{*}{$\mathrm{Cs}$} & $N_{\mathrm{V}}$ & 77 & & & & & & & \\
\hline & $N_{\text {IV }}$ & 79 & & & & & & & \\
\hline & & & $A_{d}^{+}$ & $78.1 \pm 0.2$ & $(78.7 \pm 0.2)$ & & & & \\
\hline & & & $B_{d}^{+}$ & $79.7 \pm 0.3$ & $80.3 \pm 0.2$ & & $80.1 \pm 0.1$ & & $79.9 \pm 0.3$ \\
\hline & & & $C_{d}^{+}$ & $82.4 \pm 0.3$ & $82.5 \pm 0.2$ & & $82.2 \pm 0.1$ & & $82.0 \pm 0.4$ \\
\hline & & & $D_{d}^{+}$ & 83.5 & & & & & \\
\hline & & & $E_{d}^{+}$ & $84.7 \pm 0.3$ & & & & & \\
\hline & & & $F_{d}^{+}$ & $85.7 \pm 0.2$ & $85.2 \pm 0.2$ & & $85.1 \pm 0.2$ & & $84.4 \pm 0.5$ \\
\hline & & & $G_{d}^{+}$ & $87.5 \pm 0.2$ & $\begin{array}{l}88.7 \pm 0.3 \\
(913)\end{array}$ & & $88.2 \pm 0.2$ & & \\
\hline & & & $I_{d}^{+}$ & $92.8 \pm 0.2$ & 93.2 & & $93.2 \pm 0.2$ & & $(92.5 \pm 0.4)$ \\
\hline & & & $J_{d}^{+}$ & $95.8 \pm 0.2$ & 96.1 & & $96.2 \pm 0.5$ & & $96.3 \pm 0.1$ \\
\hline & & & $K_{d}^{+}$ & & 101.1 & & $102.8 \pm 0.3$ & & $100.7 \pm 0.4$ \\
\hline & & & $L_{d}^{+}$ & & & & $110.0 \pm 0.4$ & & $105.3 \pm 0.4$ \\
\hline \multirow[t]{12}{*}{$\mathrm{Cs}$} & $N_{\text {III }}$ & 162 & & & & & & & \\
\hline & $N_{\text {II }}$ & 172 & & & & & & & \\
\hline & & & $A_{p}^{+}$ & $161.6 \pm 0.2$ & $161.7 \pm 0.4$ & & $161.7 \pm 0.4$ & & $161.7 \pm 0.4$ \\
\hline & & & $B_{p}^{+}$ & $164.3 \pm 0.2$ & $164.4 \pm 0.4$ & & & & \\
\hline & & & $C_{p}^{+}$ & $166.9 \pm 0.2$ & $167.0 \pm 0.3$ & & & & 167. \pm 0.4 \\
\hline & & & $D_{p}^{+}$ & $168.5 \pm 0.2$ & $169.5 \pm 0.3$ & & & & \\
\hline & & & $E_{p}^{+}$ & $170.7 \pm 0.2$ & $170.9 \pm 0.3$ & & & & $170.8 \pm 0.4$ \\
\hline & & & $F_{p}^{+}$ & $172.7 \pm 0.3$ & $173.2 \pm 0.4$ & & $172.6 \pm 0.4$ & & $173.2 \pm 0.4$ \\
\hline & & & $G_{p}^{+}$ & & $176.7 \pm 0.3$ & & 176 & & \\
\hline & & & $H_{p}^{+}$ & $183.0 \pm 0.3$ & $185.8 \pm 0.4$ & & & & $180.9 \pm 0.5$ \\
\hline & & & $A_{p}^{\frac{p}{p}}$ & & & & $184.4 \pm 0.4$ & & \\
\hline & & & $B_{p}^{-}$ & & & & $191.1 \pm 0.6$ & & \\
\hline
\end{tabular}

about the ionic composition of the $X$ states is available to make a detailed identification. The weak $A_{d}^{+}$peaks may be related to forbidden excitons tied to $\Gamma_{1}$.

It is interesting to point out that the $\left(A_{d}^{+}, B_{d}^{+}, \ldots\right)$ peaks move to higher energies in going from CsI to $\mathrm{CsCl}$, as usual. However, the next step, that to CsF, brings a decrease in energy which must be related to the different crystal structure of CsF (rocksalt, fcc) and the remaining Cs halides (simple cubic). It has been also shown that the fundamental edge of $\mathrm{CsCl},{ }^{21} \mathrm{CsBr}$, and $\mathrm{CsI}^{58}$ oc- curs at lower energy when crystallized in the metastable rocksalt structure.

An interesting feature of the optical structure in Figs. $5-9$ is the $I_{d}^{+}$and $J_{d}^{+}$peaks at about 93 and $96 \mathrm{eV}$. Similar values, although of weaker structure, have been observed for $\mathrm{Xe}-\sim 15 \mathrm{eV}$ above the $4 d$ threshold. ${ }^{39}$ It has been interpreted as a double excitation; a $4 d$ core electron and a $5 p$ valence electron of $\mathrm{Cs}^{+}$are excited simultaneously by a photon. The threshold for the $5 p$ excitation of $\mathrm{Cs}^{+}$is $13.0 \mathrm{eV}{ }^{30,31}$ Thus, the structure at 92-96 eV could be attributed to this mechanism. 
It is not clear, however, whether the strength of the $I_{d}^{*}$ and $J_{d}^{+}$peaks can be accounted for theoretically with double excitations. ${ }^{59,60}$

\section{Transitions from Halogen Ion}

CsBr and CsI (Figs. 8 and 9) show structure due to $\mathrm{Br}^{-} 3 d$ and $\mathrm{I}^{-} 4 d$ levels. This structure is considerably less clear than the corresponding structure of the Rb halides, due, at least in part, to the strong $d \rightarrow f$ continuum of Cs. Also, only the $B_{d}^{-}, C_{d}^{-}$, and $D_{d}^{-}$peaks are seen in $\mathrm{CsBr}$ : Higher-energy peaks associated with $\mathrm{Br}^{-} 3 d$ should fall under the strong $B_{d}^{+}, C_{d}^{+}$, and $F_{d}^{+}$peaks of $\mathrm{Cs}^{+} 4 d$. The energy difference between the $C_{d}^{-}$and $E_{d}^{-}$peaks of CsI is $1.8 \mathrm{eV}$, and hence it is possible to interpret them as a spin-orbit pair. The energies of the $B_{d}^{-}$and $C_{d}^{-}$peaks of $\mathrm{CsBr}$ also differ by $1.1 \mathrm{eV}$, close to the $\mathrm{Br}^{-} 3 d$ spin-orbit splitting. An unambiguous assignment of these peaks to a spin-orbit doublet is not possible since about the same splitting separates peaks $C_{\vec{d}}$ and $D_{\bar{d}}$.

\section{3. $\mathrm{Cs}^{+} 4 p$ Transitions}

Towards the end of the high-energy range of Figs. 6-9 $(\sim 160 \mathrm{eV})$ a peak is seen $\left(A_{p}^{*}\right)$ which can be assigned to transitions from the $4 p$ subshell of $\mathrm{Cs}^{*}$. This peak should have a spin-orbit-split mate with a splitting of about $13 \mathrm{eV}$, according to the calculations of Herman and Skillman ${ }^{44}$ for $\mathrm{Xe}(11.5 \mathrm{eV})$ and $\mathrm{Ba}(14.2 \mathrm{eV})$. The most likely candidate for the spin-orbit mate of $A_{p}^{+}$is peak $F_{p}^{*}$ of Fig. 10, which appears for all materials and yields an average spin-orbit splitting of 11.3 $\mathrm{eV}$. The calculation of Herman and Skillman seems also to overestimate the spin-orbit splitting of the $4 p$ states of Cs. We are not, at present, in a position to try to identify the remaining structure associated with these transitions shown in Fig. $10\left(B_{p}^{+}, C_{p}^{+}, D_{p}^{+}, \ldots\right)$.

Note added in proof. Following completion of the manuscript, two recent papers came to the authors's attention: (a) Y. Iguchi, Sci. Light 19, 1 (1970) and (b) F. C. Brown, C. Gähwiller, $\overline{\mathrm{H}}$. Fujita, A. B. Kunz, W. Scheifley, and N. Carrera (unpublished). Both papers overlap with parts of our measurements and show good agreement with our results.

\section{ACKNOWLEDGMENTS}

The authors are grateful to P. Rabe and G. Singmann for help in the sample preparation and parts of the alkali-halide films. Thanks are also due to D. Michael and E. W. Weiner for technical assistance during the course of experiments.
${ }^{*}$ Work supported by the Deutsche Forschungsgemeinschaft。

$\dagger$ John S. Guggenheim Memorial Foundation Fellow, on leave from Brown University, Providence, R. I.

\$Present address: Iowa State University, Ames, Ia.

${ }^{1}$ R. S. Knox and K. J. Teegarden, in Physics of Color Centers, edited by W. B. Fowler (Academic, New York, 1968), p. 1.

${ }^{2}$ W. B. Fowler, in Physics of Color Centers, edited by W. B. Fowler (Academic, New York, 1968), p. 53.

${ }^{3}$ H. Philipp, E。A. Taft, and L. Apker, Phys. Rev. 120, 49 (1960).

${ }^{4}$ S. Ballaro, A. Balzarotti, and V. Grasso, Phys. Letters 23,405 (1966).

${ }^{5} \mathrm{U}$. Gerhardt, and E。 Mohler, Phys. Status Solidi $\underline{18}$, K45 (1966).

${ }^{6} \mathrm{D}$. Fröhlich and B。Staginnus, Phys. Letters $\underline{28 \mathrm{~A}}$, 738 (1969)

${ }^{7}$ R. Hilsch and R。W. Pohl, Z. Physik 59, 812 (1930)。

${ }^{8}$ G. Baldini and B. Bosacchi, Phys. Rev. 166, 863 (1968).

${ }^{9} \mathrm{~B}$. Bosacchi, in Proceedings of the Conference on Optical Properties of Solids, edited by E. D. Haidemenakis (Gordon and Breach, New York, to be published).

${ }^{10} \mathrm{G}$. Baldini, A. Bosacchi, and B. Bosacchi, Phys. Rev. Letters 23, 846 (1969).

${ }^{11}$ M. Creuzburg, Z. Physik 196, 433 (1966)。

${ }^{12}$ M. Creuzburg, dissertation, Universität Hamburg, 1966 (unpublished).
${ }^{13}$ J. C. Phillips, Solid State Physics, Vol. 18, edited by F. Seitz and D. Turnbull (Academic, New York, 1966), p. 55 .

${ }^{14} \mathrm{C}$. W. Higginbotham, F. H. Pollak, and M. Cardona, in Proceedings of the Ninth International Conference on the Physics of Semiconductors, edited by S. H. Ryvkin (Nauka, Leningrad, 1968), Vol。I, p. 57.

${ }^{15}$ A. B. Kunz, T. Miyakawa, and W. B. Fowler (unpublished).

${ }^{16}$ A. B. Kunz, Phys.Status Solidi 29, 115 (1968).

${ }^{17}$ A. B. Kunz, J. Phys。Chem. Solids 31, 265 (1970).

${ }^{18}$ W. B. Fowler and A. B. Kunz, Phys. Rev. 186, 956 (1969)。

${ }^{19}$ Y. Onodera, J. Phys. Soc. Japan 25, 469 (1968).

${ }^{20}$ U. Rössler, Phys.Status Solidi 34, 207 (1969).

${ }^{21} \mathrm{~J}$. E. Eby, K. J. Teegarden, and D. B. Dutton, Phys。 Rev。116, 1099 (1959).

${ }^{22}$ K. Teegarden and G. Baldini, Phys. Rev. $\underline{155}, 896$ (1967).

${ }^{23}$ F. Fischer and R. Hilsch, Nachr. Akad. Wiss. Göttingen, II. Math. Physik Kl. $\underline{8}, 241$ (1959).

${ }^{24}$ G. R. Huggett and K. Teegarden, Phys. Rev. $\underline{141}, 797$ (1966).

${ }^{25}$ R. S. Knox, Theory of Excitons (Academic, New York, 1963), p. 38.

${ }^{26} \mathrm{G}$ 。 Baldini, Phys. Rev. 128, 1562 (1962).

${ }^{27}$ R. Haensel, G. Keitel, E. E. Koch, M. Skibowski, and P. Schreiber, Phys. Rev. Letters 23, 1160 (1969).

${ }^{28}$ R. Haensel, G. Keitel, E. E. Koch, M. Skibowski, and 
P. Schreiber, Opt. Commun, (to be published).

${ }^{29}$ J. C. Phillips, Phys. Rev. 136, A1714 (1964).

${ }^{30} \mathrm{H}$. Saito, S. Saito, R. Onaka, and B. Ikeo, J. Phys. Soc. Japan 24, 1095 (1968).

${ }^{31}$ C. Moore, Natl. Bur. Std。(U.S.), Circ. No. 467 (U.S. GPO, Washington, D.C.), Vol. I (1949); Vol. II (1958); Vol. III (1958).

${ }^{32}$ R. Haensel, C. Kunz, T. Sasaki, and B. Sonntag, Phys. Rev. Letters 20, 1436 (1968).

${ }^{33}$ R. Haensel, C. Kunz, and B. Sonntag, Phys. Rev. Letters 20, 262 (1968).

${ }^{34}$ R. P. Godwin, in Springer Tracts in Modern Physics, edited by G. Höhler (Springer, Berlin, 1969), Vol. 51, p. 1.

${ }^{35}$ R. Haensel and C. Kunz, Z. Angew. Phys. $\underline{23}, 276$ (1967).

${ }^{36}$ R. Haensel, C. Kunz, T. Sasaki, and B. Sonntag, Appl. Opt. 7, 301 (1968).

${ }^{37}$ G. Sauerbrey, Z. Physik 155, 206 (1959)。

${ }^{38}$ The foils were purchased from Yissum Research Development Co., Tel-Aviv, Israel.

${ }^{39}$ R. Haensel, G。 Keitel, P. Schreiber, and C. Kunz, Phys. Rev。 188, 1375 (1969).

${ }^{40} \mathrm{U}$. Fano and J. W. Cooper, Rev。Mod. Phys. 40,441 (1968)。

${ }^{41}$ F. C. Brown, C. Gähwiller, H. Fujita, N. Carrera, and W.Scheifley, in Proceedings of the Tenth European Congress for Molecular Spectroscopy, Liège, 1969 (unpublished).

${ }^{42}$ H. Fujita, C. Gähwiller, and F. C. Brown, Phys . Rev. Letters 22, 1369 (1969).

${ }^{43}$ M. Cardona and R. Haensel, Phys. Rev. B 1, 2605 (1970).
${ }^{44}$ F. Herman and S. Skillman, Atomic Structure Calculations (Prentice-Hall, Englewood Cliffs, N.J., 1963).

${ }^{45} \mathrm{~K}$. Codling and R. P. Madden, Phys. Rev. Letters 12, 106 (1964).

${ }^{46}$ Handbook of Chemistry and Physics (The Chemical Rubber Publishing Co., Cleveland, Ohio, 1968), 49th ed.

${ }^{47}$ E. O. Kane, Phys. Rev. 180, 852 (1969).

${ }^{48} \mathrm{~J}$. C. Hermanson, Phys. Rev. 150, 660 (1966).

${ }^{49}$ R. Haensel, G. Keitel, P. Schreiber, B. Sonntag, and C. Kunz, Phys. Rev. Letters 23, 528 (1969); in Proceedings of the NBS Symposium on "Electronic Density of States, "Washington, D. C., 1969 (unpublished); G. D. Mahan, Phys. Rev. 163, 612 (1967).

${ }^{50}$ J. Klima, J. Phys. C $\underline{3}, 70$ (1970); and (private communication).

${ }^{51}$ R. Haensel, G. Keitel, G. Peters, P. Schreiber, B。 Sonntag, and C.Kunz, Phys. Rev。 Letters 23, 530 (1969).

${ }^{52}$ Y. Onodera, M. Okazaki, and T. Inui, J. Phys. Soc. Japan 21, 2229 (1966).

${ }^{53}$ A. B. Kunz, Phys。 Rev. 175, 1147 (1968).

${ }^{54}$ A. B. Kunz, T. Miyakawa, and S. Oyama, Phys. Status Solidi 34, 581 (1969).

${ }^{55}$ A. B. Kunz, Phys. Rev. 180, 934 (1969).

${ }^{56} \mathrm{Y}$. Iguchi et al., Solid State Commun. $\underline{6}, 575$ (1968)。

${ }^{57}$ A. S. Vinogradov, T. M. Zimkina, and Y. F. Maltsev, Fiz. Tverd. Tela 11, 3354 (1969) [Soviet Phys. Solid State 11, $2721(1970)]$.

${ }^{58} \mathrm{~A}$. A. Gavini and M. Cardona, Phys. Letters $27 \mathrm{~A}$, 112 (1968)。

${ }^{59}$ T. Miyakawa, J. Phys. Soc. Japan 17, 1898 (1962)。

${ }^{60}$ J. C. Hermanson, Phys. Rev. 177, 1234 (1969)。

\title{
Calculation of the Internal Energy and State Populations of a Strongly Coupled Electron-Phonon System in Thermal Equilibrium
}

\author{
D. W. Howgate \\ Solid State Physics Branch, Physical Sciences Laboratory, Redstone Arsenal, Alabama 35809 \\ and \\ C. Alton Coulter \\ Department of Physics, Clark University, Worcester, Massachusetts 01610 \\ (Received 5 January 1970)
}

\begin{abstract}
Expressions are derived for the total energy and the thermal-equilibrium single-electron and phonon distribution functions for a defect electron-phonon system with a strong electronlattice distortion $V_{d}$. An application of the result is made to the case of a single-phonon mode coupled strongly to a two-level electron system.
\end{abstract}

\section{INTRODUCTION}

In the calculation of properties of trapped-electron defect centers in crystals one finds it necesary to consider the effect of the electron-phonon interaction upon the system both directly, through its effect upon the energy eigenvalues and eigenstates, and indirectly, through its effect on the thermal averages of observables. If one assumes the electron-phonon interaction Hamiltonian to have the usual form, linear in the phonon coordinates, then this interaction Hamiltonian can be divided 